\title{
Concomitant Medication Subcategory
}

National Cancer Institute

\section{Source}

National Cancer Institute. Concomitant Medication Subcategory. NCI Thesaurus. Code C83232.

A subdivision of concomitant medication data. 